\title{
Clinicopathological Study of 50 Cases Colorectal Carcinoma At Tertiary Care Hospital
}

\author{
Quddus $\mathrm{MA}^{1}$, Alimunzzaman $\mathrm{M}^{2}$, Rahman $\mathrm{MZ}^{3}$, Alam $\mathrm{MK}^{4}$
}

\begin{abstract}
Background: Colorectal carcinoma is a major causes of mortality and morbidity worldwide. Objective: The purpose of the present study was to consider the socio-demographic status and serum CEA level as diagnostic tool for advanced stages of colorectal cancer. Methodology: This analytical cross-sectional study was conducted in the Department of Surgery at Shaheed Ziaur Rahman Medical College Hospital, Bogra during the period of January 2010 to December 2011. Patients age ranged from 15 years to 75 years and above were included in this study. All efforts and available modern technologies including ultrasonography (USG), CT scan, endo-anal USG, chest X-ray were done to detect the primary site and metastasis of colorectal cancer. Result: The most frequent colorectal cancer was detected in 35-44 years age group with $60.0 \%$ male and $40.0 \%$ female patients. A total number of $41(82 \%)$ cases had been suffering from rectal carcinoma and $9(18 \%)$ with colonic cancer. Abdominal pain, anorexia, altered bowel habit, per rectal bleeding and abdominal lump were the cardinal features in clinical presentation. This study showed that serum CEA level was raised in $3(11.11 \%)$ cases with tumour size $2-5 \mathrm{~cm}$ and $21(91.30 \%)$ cases with tumor size $>5 \mathrm{~cm}$. It was observed that serum CEA level was raised in $100 \%$ cases of Dukes stage ' $\mathrm{D}$ ', $92.31 \%$ cases of stage ' $\mathrm{C}$ ' and $30.56 \%$ cases of stage 'B' colorectal cancer. The serum CEA level in relation with tumour size and stage has been proved highly significant $(p<0.001)$. Conclusion: Rectal carcinoma is found common than colonic cancer and level of serum CEA is directly related to the cancer stage.
\end{abstract}

Key words: Colon cancer, rectal cancer, socio-demographic status, serum CEA, staging, Colorectal Cancer

\section{Introduction}

Colorectal carcinoma is the second most common malignancy in male and fourth most common malignancy in female ${ }^{1}$. In spite of modern treatment modalities, it is a major cases of mortality and morbidity till date. Overall it is the second most common carcinoma in Western countries, with approximately 18,000 patients in the UK dying per year ${ }^{1}$. Although the incidence of colorectal cancer in this country is no less than the Western World, there is no broadbased study about it. Increased caloric intake and decreased intake of fibers containing foods are among the possible dietary influence for causing colorectal cancer ${ }^{2-4}$.

In the early stage of presentation, the patient may be asymptomatic or many have per rectal bleeding, tenesmus, early morning diarrhoea, unexplained anemia and weight loss may be present. Pelvic pain or back pain, indicates locally advanced disease. In this country, most of the colorectal cancer patients come to tertiary level hospital in advanced stages. Serum level of tumour marker carcino- embryonic antigen (CEA) correlated well with histological type, tumour size and Duke's staging ${ }^{1,3,5}$. Serum level of CEA has high sensitivity and acceptable specificity for indicating recurrent colorectal cancer ${ }^{4}$. In addition to clinical assessment, radiological imaging, cytology or histopathological examination and the serum level of CEA can play a valuable role in the management of Colorectal Cancer $^{5,7}$.

The aim of this study was to determine the serum level of CEA as a diagnostic tool for advanced colorectal carcinoma. The other purpose of this study was to find out the frequency of colorectal cancer among the different income groups, with significance of dietary habits among the patient as well as relation with blood group.

\section{Methodology}

This cross sectional study was conducted with colorectal cancer patients admitted in the Department of Surgery at Shaheed Ziaur Rahman Medical College Hospital

1. Dr. Md. Abdul Quddus, Junior Consultant (Surgery), Shajahanpur Upazila Health Complex, Bogra

2. Dr. Md. Alimunzzaman, Assistant Professor, Department of Radiotherapy, Shaheed Suhrawardy Medical College, Dhaka

3. Dr. Md. Zilluar Rahman, Medical Officer, Nandigran Upazila Health Complex, Bogra

4. Dr. Md. Kausar Alam, Associate Professor, Department of Anatomy, Pabna Medical College, Pabna.

\section{Correspondence :}

Dr. Md. Abdul Quddus, Junior Consultant (Surgery), Shajahanpur Upazila Health Complex, Bogra, Bangladesh; Email: nusratjahan_19@yahoo.com; Cell no.: +8801711902850 
(SZMCH), Bogra from January 2010 to December 2011 for a period of two (2) years. The sample size of the study was 50 cases of colorectal cancer patients, who were selected after confirmation with histopathological examination as adenocarcinoma. Patients presented with concurrent other malignant tumour, any diseases of colon and rectum other than adeno-carcinoma were excluded from this study. Data were collected by a semi structured questionnaire. Meticulons history were taken, physical examination was done. Biopsy of colorectal growth were taken during video colonoscopy and sent to the pathology department of SZMC for histopathogical examination. Serum samples were collected from all patients after histopathologically confirmed colorectal cancer and sent to the private diagnostice centre. Bogra for CEA assay. To observe the size of the tumour and staging of the Colorectal Cancer USG of whole abdomen, endoanal ultra sonogram, CT scan of the whole abdomen, X-ray chest were done. Socio-economic variables like age, sex, economic status, dietary preferences for all patients were recorded. A semi-structured questionnaire was used for face to face interview and an observation check list was used for collection of information by history taking, physical examination and findings of their relevant investigations. All relevant information were recorded in a redesigned data collection sheet. After collection of all relevant data it was processed accordingly.

\section{Results}

Colorectal carcinoma were observed in 50 patients The age of patients in this study ranged from 15 to 80 years with peak age between $35-44$ years (28\%) followed by 25-34 years $(24 \%)$ and mean \pm SD age was $40.9 \pm 16.06$ years (Table 1$)$.

Table 1: Age distribution of the study population $(\mathrm{N}=50)$

\begin{tabular}{lcc}
\hline Age group (Years) & Frequency & Percentage \\
\hline $15-24$ & 5 & 10.0 \\
$25-34$ & 12 & 24.0 \\
$35-44$ & 14 & 28.0 \\
$45-54$ & 7 & 14.0 \\
$55-64$ & 7 & 14.0 \\
$65-74$ & 2 & 4.0 \\
$75 \&$ above & 3 & 6.0 \\
Total & $\mathbf{5 0}$ & $\mathbf{1 0 0}$ \\
\hline
\end{tabular}

Among 50 cases of colorectal cancer male $(60 \%)$ is predominant than female $(40 \%)$ with a male $\&$ female ratio 1.5:1 (Table 2).

Table 2: Sex distribution of patients $(\mathrm{N}=50)$

\begin{tabular}{lcc}
\hline Sex & Frequency & Percentage \\
\hline Male & 30 & 60.0 \\
Female & 20 & 40.0 \\
Total & $\mathbf{5 0}$ & $\mathbf{1 0 0}$ \\
\hline
\end{tabular}

Among 50 cases majority are from the middle class which is $28(56.0 \%)$ cases followed by lower income and higher income which are $21(42.0 \%)$ cases and $1(2.0 \%)$ case (Table-3).

Table 3 : Distribution of patients according to monthly income group $(\mathbf{N}-50)$

\begin{tabular}{lcc}
\hline Socio-economic status & Frequency & Percentage \\
\hline Lower class & 21 & 42.0 \\
Middle class & 28 & 56.0 \\
Higher class & 1 & 2.0 \\
Total & $\mathbf{5 0}$ & $\mathbf{1 0 0}$ \\
\hline
\end{tabular}

The relation between different blood groups with the Colorectal Cancer has been recorded. The highest frequency is found among the 'B' group which is 19 (38\%) followed by 'O' group which is $15(30 \%)$ (Table 4$)$

Table 4 : Distribution of blood group (ABO) of patients with colorectal cancer $(\mathrm{N}=\mathbf{5 0})$

\begin{tabular}{lcc}
\hline Types of Blood group & Frequency & Percentage \\
\hline Type A & 11 & 22.0 \\
Type B & 19 & 38.0 \\
Type AB & 5 & 10.0 \\
Type O & 15 & 30.0 \\
Total & $\mathbf{5 0}$ & $\mathbf{1 0 0}$ \\
\hline
\end{tabular}

Among the study population majority of the patients were habited on mixed food containing fish, meat and vegetable. However none were truly vegetarian.

Table 5: Distribution of dietary preference of patients

\begin{tabular}{lcc}
\hline Dietary preference & Frequency & Percentage \\
\hline Fish + vegetable & 02 & 4.0 \\
Meat+ vegetable & 10 & 20.0 \\
Fish + Meat+ vegetable & 38 & 76.0 \\
Only vegetable & 0 & 0.0 \\
Others & 0 & 0.0 \\
\hline
\end{tabular}

A total number of $41(82 \%)$ patients were affected with rectal cancer while $9(18 \%)$ patients were suffered from colon cancer (Table 6).

Table 6 : Distribution of patients according to the site of colorectal cancer $(\mathrm{N}=\mathbf{5 0})$

\begin{tabular}{lcc}
\hline Site of cancer & Frequency & Percentage \\
\hline Rectum & 41 & 82.0 \\
Colon & 9 & 18.0 \\
Total & $\mathbf{5 0}$ & $\mathbf{1 0 0}$ \\
\hline
\end{tabular}

Serum CEA level is raised in $3(11.1 \%)$ cases when tumour size is 2 to $5 \mathrm{~cm}$ and $21(91.30 \%)$ cases with tumor size more than $5 \mathrm{~cm}$ (Table-7). 
Table 7: Distribution of patients according to serum CEA level in relation with tumour size

\begin{tabular}{|c|c|c|c|c|}
\hline \multirow{2}{*}{ Size of Tumour } & \multicolumn{2}{|c|}{ Serum CEA level } & \multirow{2}{*}{ Total } & \multirow{2}{*}{ p value* } \\
\hline & Normal & Raised & & \\
\hline 2 to $5 \mathrm{~cm}$ & 24 & 3 & 26 & $<0.001$ \\
\hline Above $5 \mathrm{~cm}$ & 2 & 22 & 24 & \\
\hline Total & 26 & 24 & 50 & \\
\hline
\end{tabular}

*Chi-square test is done corrected by Fishers' Exact test.

Serum CEA level is raised in $100 \%$ cases of Dukes stage 'D' of colorectal cancer, $92.31 \%$ cases in stage ' $\mathrm{C}$ ' and $30.56 \%$ cases in stage 'B' (Table 8).

Table 8: Serum CEA level according to Duke's stage of the disease.

\begin{tabular}{|c|c|c|c|c|}
\hline \multirow{2}{*}{ Stage of Tumour } & \multicolumn{2}{|c|}{ Serum CEA level } & \multirow{2}{*}{ Total } & \multirow{2}{*}{ p value* } \\
\hline & Normal & Raised & & \\
\hline Stage 'B' & 25 & 11 & 36 & $<0.001$ \\
\hline Stage 'C' & 1 & 12 & 13 & \\
\hline Stage 'D' & 0 & 1 & 1 & \\
\hline Total & 26 & 24 & 50 & \\
\hline
\end{tabular}

*Chi-square test is done corrected by Fishers' Exact test.

\section{Discussion}

Colorectal cancer is second most common malignancy in the western countries like in UK, North America, Northern Europe, Australia and Newzeland. It is the fourth most common variety of malignant tumour in women and its frequency in man is suppressed only by carcinoma of bronchus ${ }^{2}$. Approximately 18,000 patients in UK are dying per year from colorectal carcinoma ${ }^{1}$. Rectum is the most frequent site of cancer involvement colonic cancer deaths are more frequent in women than in man (11:7) but the death from rectal cancer is slightly more frequent in men $(6: 5)^{2,8}$.

In this study patients with colorectal carcinoma were taken as study population which was 50 cases. Large scale study was not possible due to lack of resource constraints. All the cases were finally diagnosed after histopathological examination. The frequency of colorectal cancer in this study were $28 \%$ in age group of 35 to 44 years followed by $24 \%$ cases in the age group 25-35 years, $14 \%$ cases in age group of $45-54$ years; $14 \%$ cases in the age group of 55-64 years, $10 \%$ cases in the age group of $15-24$ years, $6 \%$ cases in age group of 75 years and above. The mean age \pm SD of the patients in this study was $40.9 \pm 16.06$ years. However the mean age of the western study was 60 years $^{4,9}$. In this study the incidence was higher in the younger group of patients compared with western studies. The probable cause of this shifting towards younger side may be due to limited number of cases, geographical and environmental factors as well.

It was evidenced that in this study male (60\%) was predominant than female $(40 \%)$. The male to female ratio was $3: 2$. This picture also matched with the western study ${ }^{2,4,8,9}$.

This study showed that colorectal cancer is mostly prevalent among middle socio-economic class $(56 \%)$ whose monthly income was between 3000 to 7000 taka and lower income group (42\%) which was monthly income 3000 Taka and which is also matched with the other study ${ }^{2,5,6}$. High socioeconomic class has monthly income of more than 7000 taka. It was difficult to draw a definitive relation between the blood group and colorectal cancer from such a small number of cases.

This study revealed that there was a definitive relation between serum CEA level with the size of the tumour and Duke's stages of Colorectal cancer i.e. serum CEA level was significantly raised in advances stages and having $>5 \mathrm{~cm}$ of size i.e it was highest in stage D $(100 \%)$, followed by stage C (92.31\%) and stage B (30.56\%). Statistically it was highly significant in chi-square test where the $\mathrm{p}$ value was $<0.001$. this study of serum CEA level also similar to western study ${ }^{4,5,6}$. As steady increase of serum CEA level indicate the 1st evidence of tumour recurrence, where as decreasing the level after operation indicate removal of tumour successfully but stable CEA level after treatment indicate failure of treatment ${ }^{11}$. So, regular postoperative follow up of serum CEA level is important to detect recurrence of the colorectal carcinoma.

\section{Conclusion}

It can be concluded that serum CEA level is raised in advanced stage of colorectal cancer. Thus it has diagnostic as well as prognostic value. This study on colorectal cancer at $\mathrm{SZMCH}$, Bogra is quite inadequate to draw any conclusion about the over all disease pattern and effects of treatments. Multi-centered large scale study can reveal the variables more accurately. So, it is recommended to do the study with a greater involvement that can contribute a lot in future to reveal fact, which could be helpful for the management of colorectal cancer.

\section{References}

1. Russell RCG, Norman Williams, cristopher JK, Bailey \& Love's short practice of surgy. 25th ed. London: Arnold; 2007.p.1230-31.

2. Cushiari A, Steele RJC, Moossa AR. Essential Surgical practice. 4th ed.New York. Arnold 2002;581-585.

3. Guillermo BC, Autigeno MACP carcinoembryonario preoperatorio couso factor proostico independiente on cancer de colon Y reata Rev. med. chile 2004;132 (6); 331-339.

4. Regina PCH, Cristina E, Sugarbarker RW, Chang D, Panl H. Utility of CEA and 19.9 tumour markers in diagnostic and prognostic assessment of mucinous epithelial cancers of the colon. Journal of surgical oncology 2004;23:87(4):162-66

5. Carpelan-HolmstrÃM, Haglund C, Lundin J, Jarvinen H, Roberts P. Pre-operative serum levels of CA 242 and CEA predict outcome in colorectal cancer. European Journal of Cancer 1996;32(7):1156-1161

6. Jorosian $\mathrm{MH}$, The divieal usefullness and limitations of tumour markers (online) 1988 June [cited 2006 April 04]. Available from URL. hlfp terc. a cor. org/marker. html.

7. Schaffzin DM, Wong WD, Eudorectal ultrasound in the preoperative evaluation of rectal cancer. Clin Colorectal Cancer 2004;4:124-132.

8. Jackson-Thompson J, Ahmed F,German RR, Lai SM, Friedman C. Descriptive epidemiology of Colorectal cancer in the United States, 19982001. Cancer. 2006; 107: 1103-11.

9. Troisi RJ, Freedman AN, Devesa SS. Incidence of Colorectal Carcinoma in the US; an update of trends by gender, race, age, site and stage, 1975-1994. Cancer. 1995; 85: 1670-6 
10. Lindmark G, Bergstram R, Pahlman L, Glimelius B. The association of preoperative serum tumour markers with Dukes' stage and survival in colorectal cancer. Br J Cancer 1995;71(5):1090.
11. Louhimo J, Carpelana-Holmstrm M, Alfthan H, Stenman UH, Jarvinen HJ, Haglund C. Serum HCG, CA 72 and CEA are independent prognostic factors in colorectal cancer. International journal of cancer 2002;101(6):545-548. 